\title{
Spinal pain revealing brucellar spondylodiscitis: a case report
}

\author{
Lamia Oulkadi* ${ }^{*}$, Bouchra Amine, Imane El binoune, Samira Rostom and Rachid Bahiri
}

\begin{abstract}
Background: Brucellosis is an anthropozoonosis. It is an endemic disease in the Mediterranean basin. The clinical presentation is polymorphic. The osteoarticular form is the most frequent of the focal forms affecting mainly the spine. In our endemic context, the diagnosis can lead to confusion with tuberculosis.

Case presentation: We report a case of brucellar spondylodiscitis treated initially as tubercular spondylodiscitis with a good initial evolution. Then, the diagnosis was rectified towards a Brucella origin, after a clinical and biological relapse. Diagnostic confirmation was based on the isolation of Brucella spp in the disco-vertebral CT-guided biopsy and the positive Brucella serology. Then, the patient was put on three antibacterial treatments with doxycycline, rifampicin, plus streptomycin over a period of 6 months with a good evolution.

Conclusion: Brucellar spondylodiscitis is still common in the Maghreb. It is generally insidious and leads to a delay in diagnosis. The clinician must always mention it when faced with spondylodiscitis in an endemic country and ask for brucella serology.
\end{abstract}

Keywords: Brucella, Spondylodiscitis, Brucella serology, Imaging, Case report

\section{Background}

Human brucellosis is an anthropozoonosis that causes significant morbidity worldwide with more than 500,000 new cases per year $[1,2]$. It is endemic in the Mediterranean, Africa, and China [3, 4]. Brucellosis is transmitted to humans either directly through direct contact with animals infected with brucella bacteria or indirectly through the consumption of unpasteurized dairy products [2]. The clinical presentation is polymorphic. The osteoarticular form is the most frequent of the focal form with a predominance of spinal involvement in the form of spondylodiscitis [5]. There is currently a diagnostic delay in brucellar spondylodiscitis (BS), which can be explained by the lack of clinical specificity and radiological signs of this pathology. We report a case of double-stage brucellar spondylodiscitis affecting the thoracic spine.

*Correspondence: lamia.oulkadi@gmail.com

Present Address: Department of Rheumatology A, El Ayachi Hospital, Ibn Sina University Hospital, 11000 Salé, Morocco

\section{Case presentation}

A 65-year-old man with a history of poorly controlled type 2 diabetes mellitus (HbA1C: $8.8 \%$ ) on metformin and chronic smoking with 40 packs per year. One month before his admission, he presented with inflammatory back pain which was initially treated by a general practitioner as severe osteoarthritis without improvement. He was referred to a rheumatology department, and on admission, it was noted that the patient was in good general condition. The physical examination showed, at normal temperature, a painful thoracic spine on palpation with a contracture of the para-vertebral muscles with a weight loss of $3 \mathrm{~kg}$ in one month. The C-reactive protein (CRP) was $107 \mathrm{mg} / \mathrm{l}$, the erythrocyte sedimentation rate (ESR) was $77 \mathrm{~mm} / \mathrm{h}$, and the white blood cell count was normal at 8600/ $\mathrm{mm}^{3}$. The thoraco-lumbar X-ray showed disc pinch with erosions of the T5-T6 and T8-T9 vertebral body (Fig. 1) and the magnetic resonance imaging (MRI) of the thoracolumbar spine showed a spondylodiscitis involvement of the D5-D6 and D8-D9 vertebral plates, 


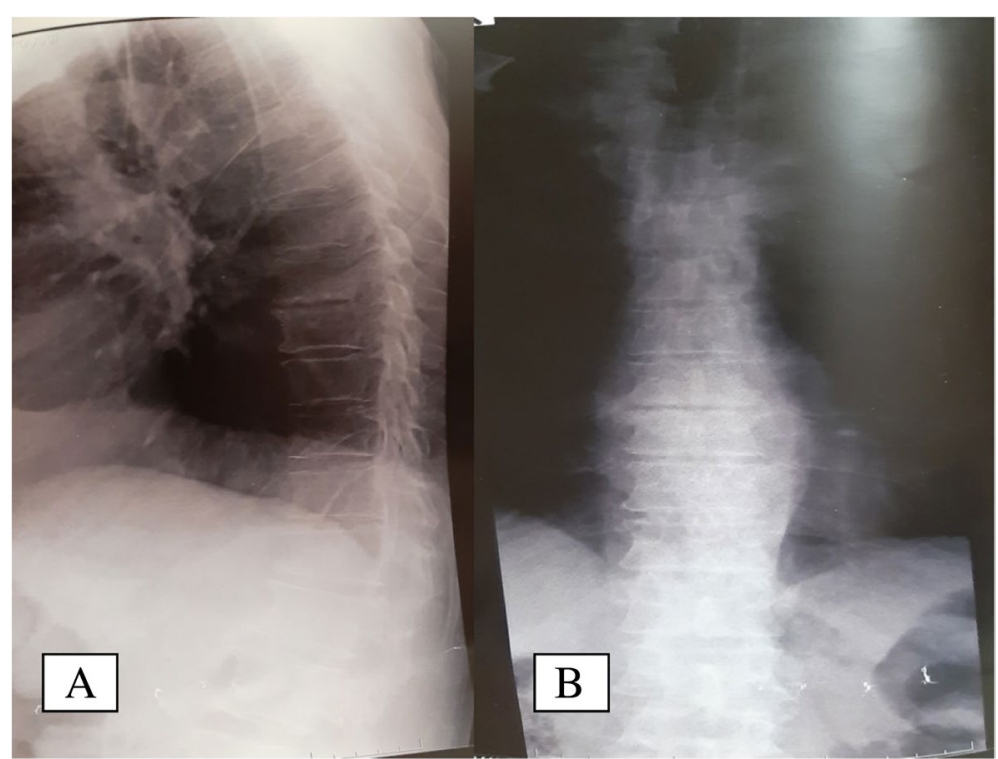

Fig. 1 The lumbar spine radiography at the front $(\mathbf{A})$ and side $(\mathbf{B})$ incidence: disc pinch with erosions of the D5-D6 and D8-D9 vertebral plates

with diffuse contrast pick up at the 2 more prominent D8-D9 stages (Fig. 2). CT-guided disco-vertebral biopsy revealed chronic spondylodiscitis lesions with osteolysis without osteogenesis or specific granulomatous foci. The bacteriological examination did not isolate a germ.
The bacteriological samples taken were negative: cytobacteriological examination of the urine, blood cultures, acid-fast bacilli sputum stains, and culture for tuberculosis. In addition, the chest X-ray showed basal opacities in bilateral bands confirmed in the chest $\mathrm{CT}$ scan with a

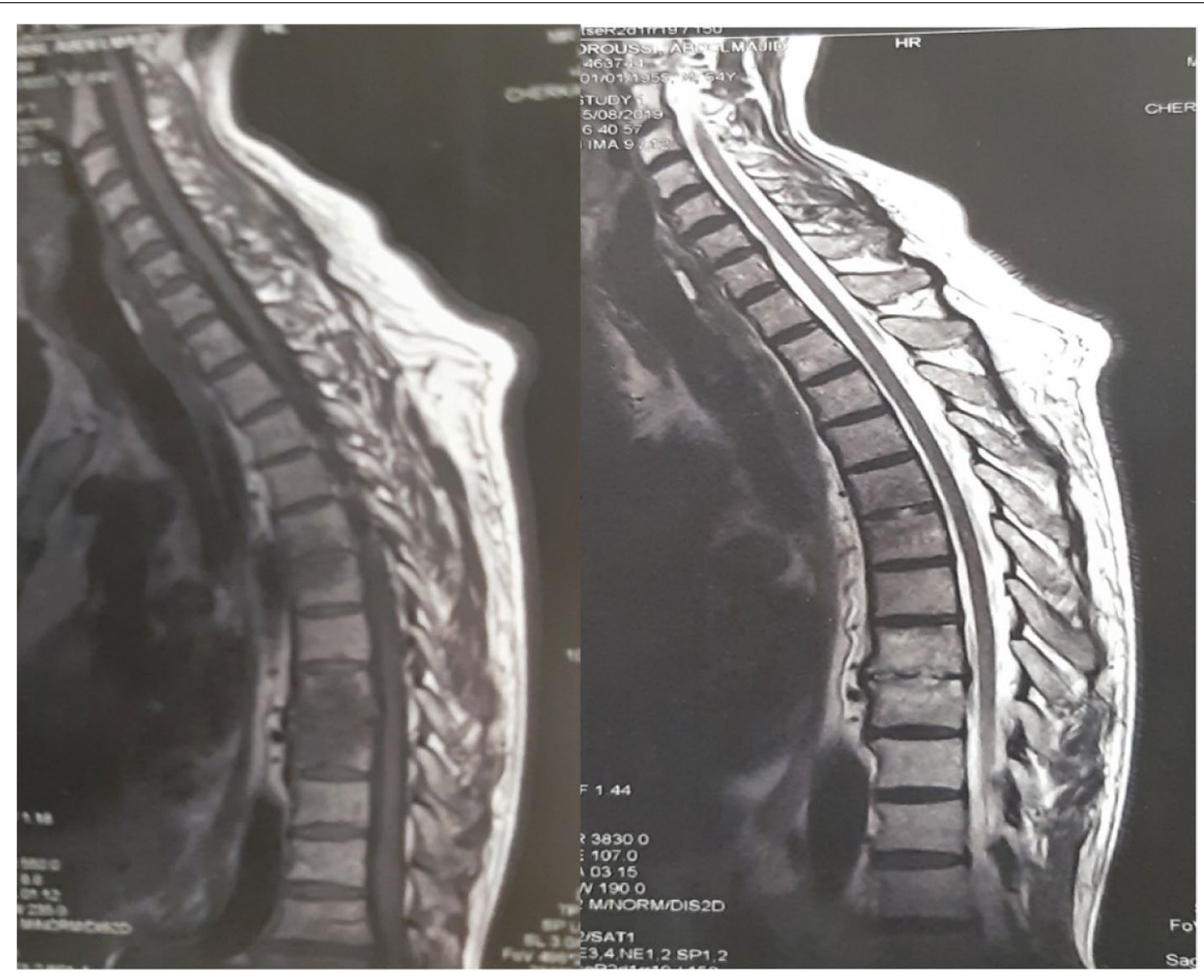

Fig. $2 \mathrm{MRl}$ of the thoracolumbar spine showing T5-T6 and T8-T9 uncovered spinal damage with contrast at the two highest levels T8-T9 
positive Quantiferon-TB Gold In-Tube test (QFT-GIT) (Fig. 3).

As a result, the diagnosis of probable tubercular spondylodiscitis after was advised by the pneumologist, in view of the chest X-ray, the positive Quantiferon, and

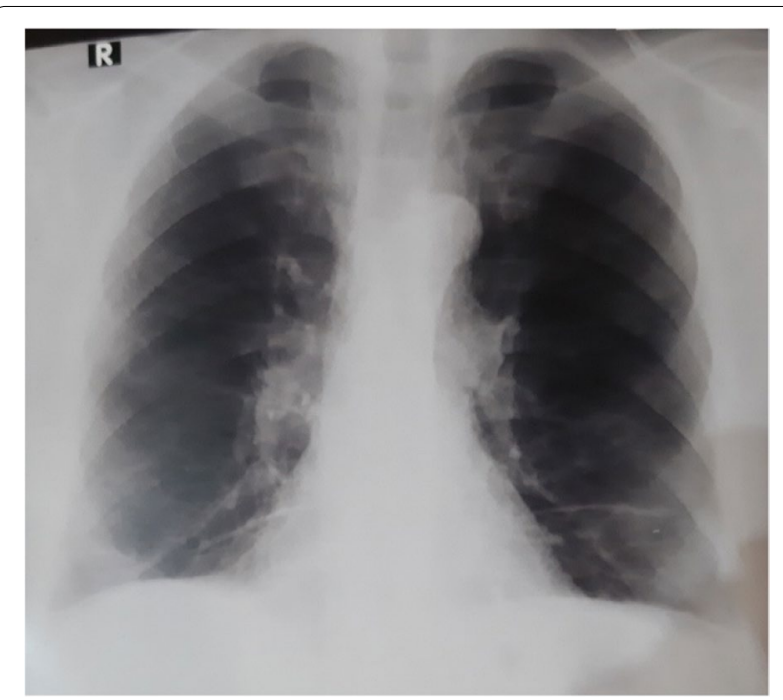

Fig. 3 Chest X-ray showing basal opacities in bilateral bands confirmed at the chest CT level the epidemic context of tuberculosis in our country. The patient was treated with antibacillary drugs (Rifampicin, Isoniazid, Pyrazinamide, Ethambutol). The evolution was favorable after 5 months with a clear improvement of the clinical symptoms and a decrease of the CRP from $109 \mathrm{mg} / \mathrm{l}$ to $6 \mathrm{mg} / \mathrm{l}$. After 5 months of treatment, the patient reported a recurrence of the clinical inflammatory symptomatology with several nocturnal awakenings associated with a febrile condition. Examination revealed a painful thoracic spine. The CRP was reassured at $24 \mathrm{mg} / \mathrm{l}$ and the MRI monitoring of the thoracic spine showed an aggravation of the T5-T6 hypersignal with the appearance of the posterior epidural abscess (Fig. 4).

The CT-guided disco-spinal biopsy was remodeled. Bacteriological exam revealed the presence of gram-negative bacilli on direct examination with identification of Brucella spp after culture. The brucella serology (Rose Bengal test, Wright test ) was positive. In retrospect, the patient claimed that he lived on a farm with a regular intake of unpasteurized milk and frequent occurrence of cow abortion. His wife's brucella serology was also positive but without any clinical symptoms. The final diagnosis selected was double-stage brucellar spondylodiscitis. So we prescribed oral doxycycline at a dose of $200 \mathrm{mg}$ and rifampicin at a $900 \mathrm{mg}$ dose over a period of 6 months plus streptomycin ( $1 \mathrm{~g} /$ day during 21 days).

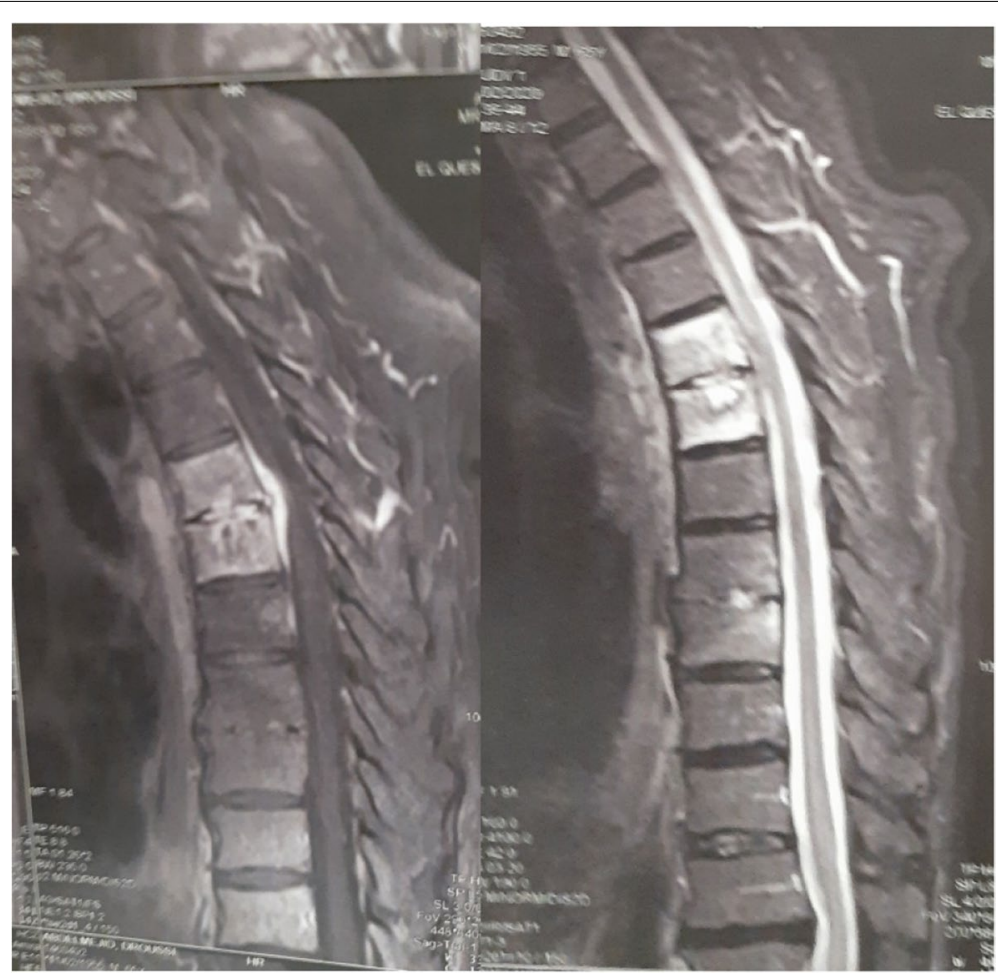

Fig. $4 \mathrm{MRl}$ of the dorsal spine with aggravation of hypersignal T5-T6 and development of a primary epidural abscess 
At the 1-year follow-up visit, there is a clear improvement on the clinical and biological levels. Thoracic and lumbar MRI had objectified the D5-6 vertebral body and intervertebral disc with sequellar lesions, and the posterior epidural abscess in the spinal canal had disappeared (Fig. 5).

\section{Discussion}

Human brucellosis, also known as Malta fever, is an anthropozoonosis caused by coccobacilli of the brucella. It has a wide global distribution with predominance in the Mediterranean basin, West Asia, the Middle East, South America, Central America, and sub-Saharan Africa [3]. It is a notifiable disease recognized as an occupational disease for individuals in contact with infected ruminants and for laboratory staff [6]. Transmission to humans occurs either directly or indirectly. Direct transmission can occur through contact with infected animals or equipment, and indirect transmission occurs through the consumption of unpasteurized dairy products [2]. The clinical manifestations of brucellosis are polymorphic. They may be acute or progressive. It most often manifests itself as a flu-like pattern of fever, sweating, anorexia, asthenia, headache, myalgia, and arthralgia. Its "sudoro-algic" form is rarely observed at present, as is the case of our patient. The spontaneous evolution of brucellosis is mainly characterized by the possibility of secondary localizations which make the severity of the disease. These may be osteoarticular, neuromeningeal, cardiac, hepatosplenic, or genital [6].

BS accounts for 6 to $85 \%$ of osteoarticular localizations [5]. The most common route of spinal contamination is hematogenous. The most frequent locations are in the lumbar spine, followed by the thoracic spine. The cervical spine is rarely affected; most often, only one disco-vertebral stage is affected [7]. Our clinical case was the double-stage involvement of the thoracic spine.

General signs are moderate and spinal pain is generally low [8]. The radiological aspect of BS makes a differential diagnosis with tubercular spondylodiscitis and spinal osteoarthritis involvement [7]. In the initial phase, the thoracic spine radiography is often normal. In the active phase, disc pinching, localized transparency of the vertebral plateau and subchondral erosions appear. This is followed by repair with osteosclerosis and osteophytosis [9]. CT scans can be used to detect disco-vertebral abnormalities before they appear on conventional radiography, with disc hypodensity being the first sign. The diagnosis is suggested by the association of erosive lesions of the vertebral body, disc pinching, and thickening of the peri-vertebral soft tissues and soft tissue infiltration and abscess [9]. MRI is the test of choice for the diagnosis of BS because of its high diagnostic sensitivity in the early phase before the onset of destructive disease [10]. MRI has an important role in early, infra-radiological, and atypical forms-localized signal abnormalities (vertebral body, anterior superior angle, isolated disc)spondylitis. For advanced forms, it allows a precise exam of the epidural extension, to the posterior arches and soft tissues, and a visualization of intra-somatic, intra-discal, epidural, and soft tissue abscesses [10]. In the acute phase, the disco-vertebral MRI signal remains non-specific (hypo signal T1, hyper signal T2, and homogeneous enhancement after contrast injection). Later on, the T1 signal of the vertebral body becomes heterogeneous and slowly normalizes if the response to treatment is acceptable [10].

The Brucella serology has a high guidance value and is often positive [11]. Brucella agglutination test (Wright test) is the World Health Organization (WHO)

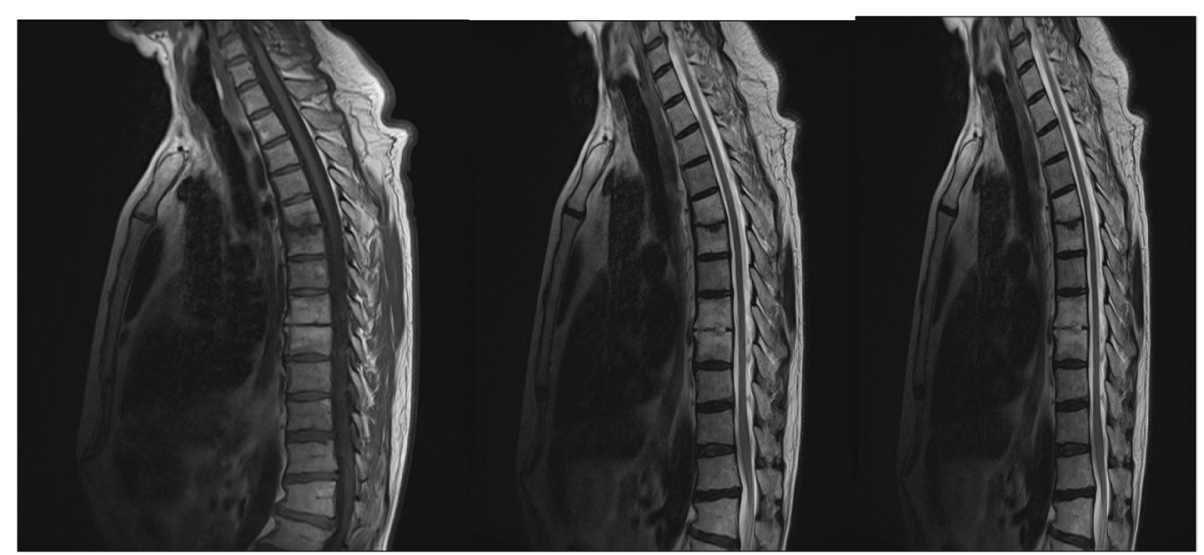

Fig. $5 \mathrm{MRI}$ of the thoracolumbar spine showing the evolution under treatment of the T5-T6 and T8-T9 brucellar destruction 
reference method. It is positive from day 10 to day 12 of the disease and quickly becomes negative as it mainly detects IgM. The antibody titer decreases in 4 to 8 months. The test is sometimes negative in subacute brucellosis and almost always negative in chronic brucellosis [11].

The Rose Bengal Test is a rapid, sensitive, and specific slide agglutination reaction. It is carried out using a bacterial suspension stained with Rose Bengal in a buffered acid medium. It allows the detection of practically all cases of brucellosis. Although it only detects IgG, it is not much later than Wright test. It is therefore very useful in the acute phase. In addition, it remains positive for a very long time and is therefore often useful in the chronic phase [12]. This method has a sensitivity of $80 \%$ and a specificity of $90 \%$. This reaction, because of its simplicity, rapidity, sensitivity, and specificity, has become the basic technique of Brucella serology, used both for the diagnosis and monitoring of brucellosis disease and for screening and epidemiological investigations [12]. Our patient had both tests positive.

The therapeutic management of BS is essentially based on antibiotic therapy. The main objective of which is to treat the acute infection, relieve symptoms, and prevent relapses. The antibiotics that are used must have good blood-brain and intracellular diffusion. The most effective agents are streptomycin, rifampin, doxycycline, trimethoprim/sulfamethoxazole, ciprofloxacin, and gentamicin [13]. The recommended treatment regimens for the treatment of the disease are mainly based on two or three antibiotics. The antibiotic therapy recommended by the WHO is represented by doxycycline (100 mg twice daily) plus rifampicin $(600 \mathrm{mg}$ /day) plus streptomycin (1 g/day IM, 21 days) over 6 months [14, 15]. After 3 weeks, after discontinuation of streptomycin therapy, patients are treated with doxycycline plus rifampin therapy alone. The average duration of treatment is 3 to 6 months. On the basis of these recommendations, we have chosen to treat our patient with doxycycline plus rifampicin and streptomycin over a period of 6 months. For patients with contraindications to cyclines (e.g., pregnancy), trimethoprim/sulfamethoxazole therapy could be an alternative. Surgery may be necessary for patients with, in particular, spinal abscess or spinal cord compression. Prevention is based on the control and elimination of infection in animals (serological surveillance, slaughter of infected animals, and vaccination of young animals) as well as pasteurization of milk. There is no vaccine for human use. BS is generally insidious and leads to a delay in diagnosis. The clinician must always mention it when faced with spondylodiscitis in an endemic country and ask for brucella serology.

\section{Conclusion}

BS is still common in the Maghreb. It is generally insidious and leads to a delay in diagnosis. The clinician must always mention it when faced with spondylodiscitis in an endemic country and ask for brucella serology. The diagnosis is based on the positivity of the cultures. The evolution is favorable under adequate medical treatment.

\section{Abbreviations}

BS: Brucellar spondylodiscitis; CRP: C-reactive protein; ESR: Erythrocyte sedimentation rate; MRI: Magnetic resonance imaging; QFT-GIT: Quantiferon-TB Gold; WHO: World Health Organization.

\section{Acknowledgements}

LO would like to thank all coauthors: Bouchra Amine, Imane El binoune, Samira Rostom, and Rachid Bahiri.

\section{Authors' contributions}

LO drafted the manuscript and reviewed the literature. BA and IE participated in the article writing and reviewed critically the manuscript. SR and RB reviewed critically the manuscript. The authors have read and approved the manuscript.

\section{Funding}

We did not receive any specific grant from funding agencies in the public, commercial, or not-for-profit sectors.

Availability of data and materials

Not applicable.

\section{Declarations}

Ethics approval and consent to participate

Not applicable.

\section{Consent for publication}

Written informed consent for publication was obtained from the patient.

\section{Competing interests}

The authors declare that they have no competing interests.

Received: 2 July 2021 Accepted: 23 November 2021

Published online: 19 December 2021

\section{References}

1. Rubach MP, Halliday JE, Cleaveland S, Crump JA (2013) La brucellose dans les pays à faible revenu et à revenu intermédiaire. Curriculum Vitae Infect Dis. 26(5):404-412. https://doi.org/10.1097/QCO.0b013e3283638104

2. Atluri VL, Xavier MN, de Jong MF, Den Hartigh AB, Tsolis RM (2011) Interactions des espèces de brucella pathogènes pour l'homme avec leurs hôtes. Annu Rev Microbiol 65:523-541. https://doi.org/10.1146/annur ev-micro-090110-102905

3. Tan KK, Tan YC, Chang LY et al (2015) Une analyse phylogénétique complète du génome basée sur les SNP révèle l'origine et la propagation mondiale de la brucella melitensis. BMC Génomique 16:93. https://doi. org/10.1186/s12864-015-1294-X

4. Lai S, Zhou H, Xiong W et al (2017) Changing epidemiology of human brucellosis, China, 1955 2014. Emerg Infect Dis. 23(2):184-194. https://doi. org/10.3201/eid2311.170833

5. Chelli Bouaziz M, Ladeb MF, Chakroun M, Chaabane S (2008) Spinal brucellosis: a review. Skeletal Radiol 37:785-790

6. Janbon F (2000) Brucellose. EMC - Maladies Infectieuses 8-038-A-10:11 
7. Tekaya R, Tayeb MH, El Amri N, Sahli H, Saidane O, Mahmoud I, Abdelmoula L (2015) Spondylodiscite à Brucella: une étude de dix-neuf cas. Ann Rheum Dis 74:290

8. Raptopoulou A, Karantanas AH, Poumboulidis K, Grollios G, RaptopoulouGigi M, Garyfallos (2006) Spondylodiscite brucellaire: atteinte multifocale non contiguë de la colonne cervicale, thoracique et lombaire. A Imagerie clinique 30(3):214-217

9. Loubes-Lacroix F, Gozlan A, Cognard C, Manelfe C (2004) Imagerie diagnostique de la spondylodiscite Infectieuse. EMC - Radiologie. 1:293-316

10. Bozgeyik Z, Aglamis S, Bozdag PG, Denk A (2014) Résultats de l'imagerie par résonance magnétique de la brucellose musculo-squelettique. Imagerie clinique. 38(5):719-723

11. Lebre A, Velez J, Seixas D, Rabadão E, Oliveira J, Saraiva da Cunha J, Silvestre AM (2014) La spondylarthrite brucellaire: série de cas des 25 dernières années. Acta Med Port. 27(2):204-210

12. Turkmani A, loannidis A, Christidou A, Psaroulaki L, Tselentis Y (2006) In vitro succeptibilities of Brucella melitensis isolates to eleven antibiotics. Ann Clin Microbiol 5:1-4

13. OMS (2006) Brucellose chez I'homme et l'animal Genève: organisation mondiale de la santé, Disponible à l'adresse: https://apps.who.int/iris/ han $\neg$ dle/10665/43597. Consulté le 27 septembre 2019.

14. Pappas G, Papadimitriou P, Christou L, Akritidis N (2006) Future trends in human brucellosis treatment. Expert Opinions Investig Drug 15:1141-1149

15. Zheng R, Xie S, Lu X, Sun L, Zhou Y, Zhang Y et al (2018) A systematic review and meta-analysis of epidemiology and clinical manifestations of human brucellosis in China. Biomed Res Int 2018:5712920

\section{Publisher's Note}

Springer Nature remains neutral with regard to jurisdictional claims in published maps and institutional affiliations.

\section{Submit your manuscript to a SpringerOpen ${ }^{\circ}$ journal and benefit from:}

- Convenient online submission

- Rigorous peer review

- Open access: articles freely available online

- High visibility within the field

- Retaining the copyright to your article

Submit your next manuscript at $\gg$ springeropen.com 